to isometric exercise in patients with neurocirculatory asthenia, a syndrome of easy fatigability without signs of organic disease. ' Our patients with asthenia and healthy controls were all young men. The isometric work was done by squeezing a rubber ball at a force $20 \%$ of the maximal squeezing force for one minute. During this handgrip test the average increase in heart rate was similar in the two groups, and the diastolic blood pressure increased slightly $(\mathrm{p}<0.05)$ more in the asthenic group $(18 \mathrm{~mm} \mathrm{Hg})$ than in the control group $(12 \mathrm{~mm} \mathrm{Hg})$. Especially interesting was the fact that the increase in blood pressure was associated with an increase in the total peripheral vascular resistance in the asthenic patients but was due to an increase in cardiac output in the controls. Our conclusion was that in patients with neurocirculatory asthenia central regulation of haemodynamics during isometric exercise is different from that in healthy controls.

Thus we agree with Dr Stokes and coworkers that the easy fatigability in these patients is of central origin. The possible aberration in the circulatory regulation during isometric exercise which we observed in our asthmatic patients emphasises the fact that poor motivation is not the only form of "central impairment" that can explain the easy fatigability in effort syndromes.

MATTI MÄNTYSAARI

Department of Clinical Physiology,

Kuopio University Hospital,

1 Mäntysaari MJ, Antila KJ, Peltonen TE. Blood pressure reactivity in patients with neurocirculatory asthenia. Am $f$ Hypertension 1988;1:132-9.

\section{Risk of breast cancer after pregnancy}

Dr Paolo Bruzzi and his colleagues (29 October, $\mathrm{p}$ 1096 ), in comparing women with breast cancer and matched controls, confirmed the well known protective effect of an early first full term pregnancy.

However, they found evidence (although it did not reach statistical significance) of an increasing relative risk with increasing parity in women aged less than 40 and a decreasing risk with increasing parity in older women. Although the trends were very small, Dr Bruzzi and others tried to incorporate them into a model whereby pregnancy acts as an anti-initiator of breast carcinogenesis (by inducing differentiation) but acts also as a promoter by accelerating the growth of a clone of cells that has already been transformed by a carcinogenic initiator. They explained the difference between the younger and older women by postulating that the promoting effect of pregnancy lasts for only five to ten years and that the younger women were close enough in time to their pregnancies to be still under the influence of the promoting effect, whereas the older women were largely not.

There seems no need to attempt to explain the minuscule trends found by the authors, but the following point is worth making. If carcinogenic initiation is a "spontaneous" process resulting from the intrinsic instability of DNA (with or without the operation of ubiquitous endogenous and exogenous factors) the probability of spontaneous initiation of an autonomous clone in creases with age (though its subsequent progress is subject, in some tissues, to important modulation by promoters and antipromoters) and older women are more likely to have such initiated clones in their breasts and should be more, rather than less, vulnerable to the influence of promoters. The suggestion that the promoting effect of pregnancy is of limited duration is therefore crucial to the model. The suggestion does not seem plausible, since if the effect of pregnancy is merely to acclerate the growth of breast tissue that effect on the size of a malignant clone would be permanent, and the point at which the clone reached a clinically detectable size would be permanently advanced.

I believe that we are still some distance away from a model that accurately describes the role of pregnancy - or, indeed, other circumstances in which the endocrine state is altered-in the promotion or inhibition of breast cancer.

\section{Schering Health Care Ltd,
Burgess Hill,}

West Sussex RH15 9NE

\section{Aspirin for strokes and transient ischaemic attacks}

Dr Peter Sandercock (22 October, p 995) firmly rejects the notion of low dose aspirin despite its theoretical advantages ${ }^{1}$ on the grounds that the published trials all used higher doses. While correct in relation to stroke, this ignores the apparently greater value of low dose aspirin in preventing myocardial infarction, as shown in the comparison between the United States physicians' health study, where $325 \mathrm{mg}$ on alternate days nearly halved the risk of myocardial infarction, and the British study, where the same dose daily had no effect. ${ }^{3}$ That such an effect might not be confined to myocardial infarction is suggested by our study, which compared the effects of $600 \mathrm{mg}$ of aspirin twice a week with placebo on a domiciliary sample of elderly patients with vascular dementia. We showed a significant benefit of aspirin over placebo with a lower risk of complications $(n=20$; $t=2 \cdot 13 ; \mathrm{p}<0 \cdot 02)(\mathrm{J} M$ Kellett $e t$ al, unpublished).

Department of Geriatric Medicine,

St George's Hospital Medical School,

London SW $170 \mathrm{RE}$

1 Rasmanis G, Vesterquist O, Green K, Edhag O, Henriksson P. Effects of intermittent treatment with aspirin on thromboxane Effects of intermittent treatment with aspirin on thromboxane
and prostacyclin in patients with myocardial infarction. Lancet and prostacyclin

2 Steering Committee of the Physicians' Health Study Research Group. Preliminary report findings for aspirin component for the ongoing physicians' health study. $N$ Engl f Med 1988;318: $262-4$

3 Peto R, Gray R, Collins R, et al. Randomised trial of prophylactic daily aspirin in British male doctors. Br.Med $\mathcal{F}$ 1988;296:313-6.

\section{I don't want you to see a psychiatrist}

Dr Greg Wilkinson highlights the important role general practitioners have in treating patients with psychiatric problems (5 November, p 1143). Kaeser and Cooper reviewed the factors influencing which patients were selected for hospital referral and which were treated by the general practitioner alone.' The selection of cases for specialist care was heavily influenced by several non-clinical factors, including conduct abnormality, social problems, and pressure from the patient or relatives. There was selective referral of men, young people, and the single.

Recent attempts have been made to bring specialist care into the general practitioner's surgery with the establishment of primary care outpatient clinics. Brown et al reported that this increased the referral rate of women. ${ }^{2}$ Despite these moves, however, and the non-psychiatric services that general practitioners can call on, the vast bulk of psychiatric disease will be treated by the general practitioner alone.

Against this background it is important to emphasise the role that the psychiatrist could have in education. Huston reports on attempts made by rheumatologists to teach general practitioners in their surgeries. ' We now know that, for depression at least, early effective treatment is the best prevention against chronic disease ${ }^{4}$ As $12-15 \%$ of patients with depression remain depressed for two years there is room for improvement. Also women and the elderly are more at risk of developing chronic conditions, and these are the very groups not referred for specialist care.

L MYNORS-WALLIS

Maudsley Hospital

London SE5 8AZ

1 Kaeser AC, Cooper B. The psychiatric outpatient, the genera practitioner and the outpatient clinic. Psychol Med 1971;1 312-25

2 Brown RMA, Strathdee G, Christie-Brown JRW', Robinson P. A comparison of referrals to primary care and hospital outpatien clinics. Br f Psychiatry 1988;153:168-73.

3 Huston GJ. An offer of rheumatology training: a failure to influence clinic referrals. Br.Med $\mathcal{7}$ 1988;296:1773

4 Scott J. Chronic depression. Br f Psychiatry 1988;153:287-97.

\section{Determining power in clinical trials}

It is a pity that Dr Peter Urbach's recommendation (5 November, p 1192) of Bayesian statistics, with which I wholeheartedly agree, should be made in the context of an ill founded attack on more conventional methods.

Two things need to be borne in mind when thinking about the power (or the type II error rate) of a statistical significance test. Firstly, as a concept it is only appropriate as a planning aid before obtaining the relevant observations, and, secondly, it is not a single number (like the significance level) but a function of the size of the true effect. Dr Urbach's tulip example is unrealistic, but it does illustrate the Cromwell principle ("I beseech you in the bowels of Christ consider that you might be mistaken"). If the experimenter proceeds on the basis that the success rate, in tulip bulb sample or clinical trial, can only be exactly $40 \%$ or exactly $60 \%$ with no other possibilities considered, she is bound to get into difficulties. Not even the most devoted classical statistician, given any slight aquaintance with real data, would fall into this trap.

M J R HEALY

Department of Epidemiology

and Population Sciences,

London School of Hygiene and Tropical Medicine, London WCIE 7HT

\section{Acute failure of artificial heart valves}

Mechanical prostheses indeed remain an imperfect substitute for heart valves (Professor Ken Taylor, 22 October, p 996). The rates of acute failure for both the Duramedics bileaflet and the Medtronic single leaflet are, however, encouragingly low. Perhaps one of the most commercially successful of the mechanical valves is the Starr-Edwards valve, which incorporates a ball in a cage. Over 140000 of the currently marketed models have been implanted world wide.

We have recently reviewed a necropsy series of 36 Starr-Edwards valves obtained from patients who had died suddenly. The valves had been implanted over a number of years since 1966, with patient survival ranging from one week to 18 years. In 15 of the patients the aortic root had become distorted to a variable degree because the cage frame had formed a narrowed triangular outlet to such an extent that it interfered with the free movement of the ball. The elastic aortic wall conformed to the angulated contour, with the distance from the centre of the cage to the midpoint of the flattened sides being less than the ball radius. The movement of the ball was thus impeded, 